Using log diaries to record experience before taking membership or fellowship examinations is well established in some disciplines and could be used by senior house officers. Such a record should include the educational objectives for the post together with a system for recording whether these have been achieved and applied. Any problems could be recorded for discussion. This record should be regularly reviewed by the educational supervisor, whose responsibility would be to ensure that senior house officers had every opportunity to meet their specified objectives and that any gaps in relevant experience were readily identified and rectified. Other members of staff could also refer to the record to ensure the relevance of teaching and to avoid duplication.

After personal educational objectives have been set for each doctor the educational process should be completed by assessment of whether these objectives have been fulfilled. Senior house officers could also be assessed in terms of whether their performance in post is satisfactory. For trainee general practitioners satisfactory completion is mandatory under the terms of the NHS (vocational training) regulations. Assessment of both performance and educational achievement could benefit senior house officers provided that it occurred sufficiently early in the post to enable improvements to be made.

It would therefore be appropriate for senior house officers to have a formal assessment session with their educational supervisor part of the way through the post and again at its completion. Assessment is likely to have educational value, however, only if the outcome is fed back to the senior house officer. Arguably, assessment of performance should not be mixed with educational supervision, though manpower considerations might necessitate such a dual role for the educational supervisor. Feedback from the department to the senior house officers would close the educational loop. It would also be helpful if departments could receive feedback from the senior house officers on the quality of their education.

Pilot schemes should now be initiated in several regions and compared with traditional models. Implications for funding could then be deduced and a national policy for training senior house officers established. Given that they will have their hands on the purse strings, postgraduate deans will be able to insist on substantial improvements in the educational content of senior house officer posts. They must act on this opportunity to ensure that young doctors working in the NHS receive the training that they need and deserve.

MAUREEN BAKER

Office of the Postgraduate Dean, Clinical research fellow

University of Nottingham,

Nottingham NG7 2UH

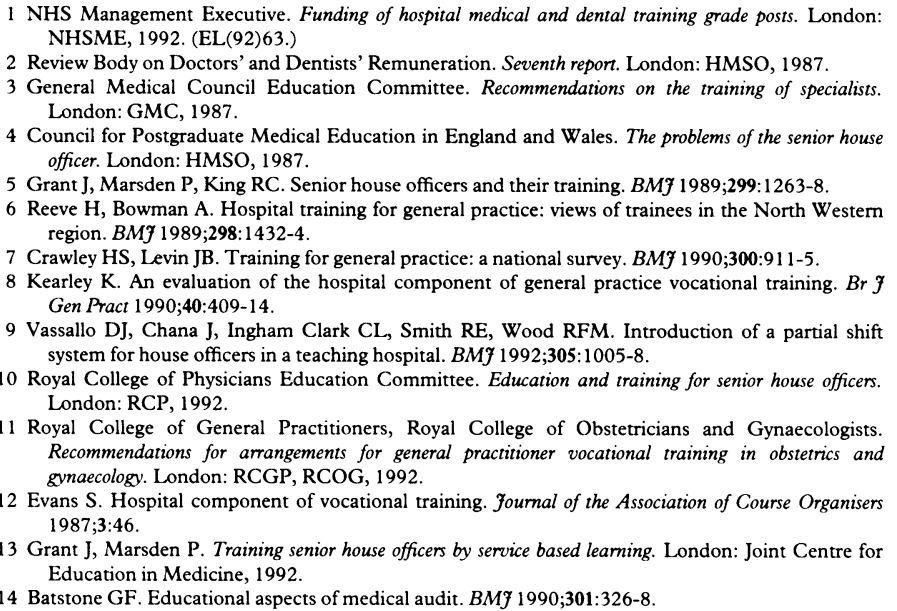

Urinary incontinence is common. In a survey reported in this week's journal MORI interviewed 4000 people aged 30 and over in their own homes on behalf of the British Association for Continence Care (p 832). ${ }^{1}$ It found that $14 \%$ of women had experienced urinary incontinence, $5.7 \%$ within the preceding week; the corresponding figures for men were about half these. Other studies have reported the difference between the sexes $^{2}$ and suggested a prevalence of urinary incontinence in adult women leading independent lives of between $22 \%$ and $45 \%$. $^{3-5}$

Whichever estimate is closest to the true prevalence, urinary incontinence is undoubtedly common in apparently healthy people, especially women. Among women, the prevalence rises with increasing age and parity and deteriorating general health. ${ }^{246}$ But even young, nulliparous, and otherwise totally healthy women experience urinary incontinence..$^{24}$

Although urinary incontinence may be no more than a nuisance in some women, for many it is far more troublesome. ${ }^{5}$ Some two thirds of women for whom incontinence occurs at least weekly regularly wear some sort of protection (such as a pad) before leaving home. ${ }^{3}$ They substantially change their lifestyles, restricting normal day to day activities such as shopping, travel, physical recreation, and choice of clothing. ${ }^{137}$ Incontinent women believe that their incontinence has affected their physical or mental health, ${ }^{7}$ and they may develop difficulties in relationships with family and friends. In a recent survey one in five incontinent women were afraid that they smelt and one in nine believed that sexual activity was compromised. ${ }^{7}$ In the MORI survey only $13 \%$ of incontinent people had ever confided their problem to their spouse.

Incontinent adults seem to have limited confidence in the medical and allied professions. Although half the incontinent people in the MORI survey had consulted their general practitioner, other surveys have suggested a much lower proportion. ${ }^{45}$ No single explanation exists for this. Clearly, some people do not consider that their problem is serious while others do not attend because of embarrassment or fear of surgery. ${ }^{13}$ One study found that nearly two thirds of patients had had their incontinence for over two years before they first sought professional advice. ${ }^{8}$ More than $90 \%$ of incontinent people, however, considered that their general practitioner would be sympathetic or helpful to their problem $^{14}$; almost half would welcome some form of treatment. ${ }^{9}$

What form should treatment take? Most incontinent women have either genuine stress incontinence or detrusor instability, or both, yet distinguishing between these two on the basis of symptoms is impossible in a quarter of patients. ${ }^{10}$ Although symptoms may give some guide to the severity of 
the incontinence, they do not distinguish absolutely between genuine stress incontinence and detrusor instability. But not every incontinent patient requires referral to a urodynamic unit. If she complains of stress incontinence but denies any urgency or urge incontinence her doctor can safely assume that she has genuine stress incontinence. Treatment with pelvic floor exercises produces improvement in $70 \%$ of cases and continence in $40 \% .^{11}{ }^{12}$

If the patient complains of urgency and urge incontinence but denies any stress incontinence; if the history and examination yield no other abnormal features; and if the urine tests negative for protein, glucose, red cells, white cells, and microorganisms then detrusor instability is the likely diagnosis and the patient should be treated accordingly. Behavioural treatments, such as bladder retraining, are time consuming but effective, making up to $90 \%$ of patients continent. ${ }^{13}$ Drug treatment requires less skill but is less effective. The current drug of choice is oxybutynin, which in divided daily doses of between 5 and $15 \mathrm{mg}$ may improve symptoms in up to $70 \%$ of patients but will make only half of them continent. Its side effects of dry mouth and blurred vision are common. ${ }^{14}$

Patients who fail to respond to these regimens or whose symptoms do not allow an accurate clinical diagnosis should be referred. For women it matters less whether they are referred to a gynaecologist or a urologist than that they are referred to someone with an interest in urinary incontinence. If surgery for genuine stress incontinence is required suprapubic surgery is generally more likely than vaginal surgery to make the patient continent, although the risk of complications is higher. ${ }^{15}$
Clearly, doctors see only a small proportion of patients with urinary incontinence. Potential patients should know that we have much to offer them in alleviating symptoms and improving their lifestyle, even if currently the options are limited and imperfect.

Department of Urogynaecology,

G JJARVIS

St James's University Hospital,

Leeds LS9 7TF

1 Brocklehurst J. Urinary incontinence in the community-analysis of a MORI poll. BM 1993;306:832-4

1980;281:1243-5.

Lagro-Janssen TLM, Smits AJA, van Weel C. Women with urinary incontinence: self-perceived worries and general practitioners' knowledge of the problem. Br f Gen Pract 1991;40:331-4.

4 Jolleys JV. Reported prevalence of urinary incontinence in women in a general practice. $B M 7$ 988;296:1300-2.

5 Yarnell JWG, Voyle GJ, Richards CJ, Stephenson TP. The prevalence and severity of urinary incontinence in women. $f$ Epidemiol Community Health 1981;35:71-4.

6 Vetter MJ, Jones DA, Victor CR. Urinary incontinence in the elderly at home. Lancet 1981; 1275-7.

Wyman JF, Harkins SW, Choi SC, Taylor JR, Fantl JA. Psychosocial impact of urinar incontinence in women. Obstet Gynecol 1987;70:378-81.

8 Macaulay AJ, Stern RS, Holmes DM, Stanton SL. Micturition and the mind: Psychological factors in the aetiology and treatment of urinary incontinence in women. $B M$ 1987 $^{2}$ 1994:540-3.

O'Brien J. Austin M, Sethi P, O'Boyle P. Urinary incontinence: prevalence, need for treatment, and effectiveness of intervention by nurse. BMJ 1991;303:1308-12.

10 Jarvis GJ, Hall S, Stamp S, Millar DR, Johnson A. An assessment of urodynamic examination in arvis GJ, Hall S, Stamp S, Millar DR, Johnson A. An as
incontinent women. Br f Obstet Gynaecol 1980;87:893-6.

11 Olah KS, Bridges N, Denning J, Farrar DJ. The conservative management of patients with symptoms of stress incontinence. Am f Obstet Gynecol 1990;162:87-92.

12 Peattie AB, Plevnik S, Stanton SL. Cones: a conservative method of managing genuine stres incontinence. Br f Obstet Gynaecol 1987;89:1026-30

13 Jarvis GJ, Millar DR. Controlled trial of bladder drill for detrusor instability. BMJ 1980;281: $1322-3$.

14 Moore $\mathrm{KH}$, Hay DM, Imrie AE, Watson A, Goldstein M. Oxybutynin hydrochloride in the treatment of women with idiopathic detrusor instability. Br f Urol 1990;66:479-85.

15 Hilton P. Which operation for which patient? In: Hilton P, Drife JO, Stanton SL. Micturition London: Springer-Verlag, 1989:225-46.

\title{
Filtering white cells from blood for transfusion
}

\author{
Some benefits but expensive
}

White cells in donor blood may cause problems like fever and infection in recipients, and $99.9 \%$ of them can be removed with modern filters. Some haematologists thus believe that all blood should be routinely filtered, and something like four million filters were used in the United States last year. Routine filtration in Britain could cost the NHS more than $£ 40 \mathrm{~m}$ a year. Particular circumstances exist in which filtration may be useful, and a consensus conference held at the Royal College of Physicians in Edinburgh tried to identify them.

Few randomised controlled trials have been conducted using filtered blood, and most of them have been small, unblinded, and concerned with laboratory rather than clinical end points.' Filtered blood is widely used to treat recurrent non-haemolytic febrile reactions in patients who depend on regular blood transfusions. The reactions will generally not recur if $90 \%$ of the white cells are removed, and this can be achieved either by using a filter at the bedside or by removing them in the laboratory. To prevent the reactions from occurring in the first place, filtered blood has to be used from the very first transfusion and $99 \%$ of white cells have to be removed. Unfortunately, removing this many cells at the bedside seems to be hard to achieve in the NHS. The panel, nevertheless, put this indication in the recommended category along with giving filtered blood to prevent the transmission of cytomegalovirus in patients seronegative for antibodies to the virus. Again $99 \%$ of cells must be removed to prevent transmission of infection, and in many communities-includ- ing Britain-it is usually more cost effective to transfuse blood screened for cytomegalovirus.

In several countries filtered blood is recommended in patients needing multiple transfusions to prevent HLA alloimmunisation and platelet refractoriness, which may lead to unstoppable bleeding. The Edinburgh panel decided, however, that HLA alloimmunisation was simply a laboratory end point and that the evidence was inconclusive that filtered blood prevented platelet refractoriness. Some evidence is available that the use of filtered blood in surgical patients may reduce rates of postoperative infection and of recurrence of cancer, but other studies have yielded negative results. The panel concluded that these amounted to only possible indications.

The panel was confident that filtered blood was not indicated to prevent graft versus host disease (irradiation of donor blood is better and cheaper); to prevent transmission of HIV or hepatitis B and C viruses; or in patients undergoing routine surgical procedures (with the possible exception of patients with cancer). Any further increase in the use of filters should await, the panel concluded, much more rigorous studies on the quality of life and on costs and benefits.

RICHARD SMITH $B M \mathcal{F}$

1 Lane TA, Anderson KC, Goodnough LT, Kurtz S, Moroff G, Pisciotte PT, et al. Leukocyte reduction in blood component therapy. Ann Intern Med 1972;117:151-62. 